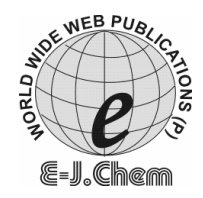

http://www.e-journals.net
ISSN: 0973-4945; CODEN ECJHAO

E-Journal of Chemistry 2009, 6(3), 729-736

\title{
Removal of Nickel(II) from Aqueous Solutions by Adsorption with Modified ZSM- 5 Zeolites
}

\author{
P. PANNEERSELVAM*, V. SATHYA SELVA BALA, N. THINAKARAN, \\ P. BASKARALINGAM, M. PALANICHAMY ${ }^{\S}$ and S. SIVANESAN
}

\author{
Environmental Management Laboratory, \\ Department of Chemical Engineering, A. C. Technology, \\ Anna University, Chennai 600 025, Tamilnadu, India. \\ ${ }^{\S}$ Department of Chemistry, Anna University, Chennai-25, India. \\ sivanesh@yahoo.com
}

Received 15 November 2008; Accepted 12 January 2009

\begin{abstract}
The sorptive removal of nickel ion from aqueous solutions using modified ZSM-5 zeolites was investigated. Experiments were carried out as a function of solute concentration and different temperatures. Mesoporous material of ZSM-5 zeolite was modified with phosphoric acid by wet method. The modified zeolite was converted to $\mathrm{Na}^{+}$form using aqueous $\mathrm{NaHCO}_{3}$ solution. The $\mathrm{Na}^{+}$form of modified zeolite, represented as $\mathrm{PNa}_{2}-\mathrm{ZSM}-5$ was characterized by XRD, BET, SEM and AAS techniques. It was then tested for ion exchange with aqueous $\mathrm{Ni}\left(\mathrm{SO}_{4}\right)$ solution. The $\mathrm{Ni}^{2+}$ content of the solution was analyzed by AAS. Phosphoric acid modified $\mathrm{PNa}_{2}-\mathrm{ZSM}-5$ zeolite shows higher adsorption capacity than the parent $\mathrm{Na}-\mathrm{Y}$ zeolite. Equilibrium modeling data were fit to linear Langmuir model then the Freundlich model. These parameter confirmed that sorption of $\mathrm{Ni}^{2+}$ is feasible spontaneous and endothermic.
\end{abstract}

Keywords: Nickel removal, Modified zeolites, Ion exchange, Isotherms.

\section{Introduction}

Several environmental and health problems, associated with the metal contamination of the natural systems (soil and water) are arising from mining industries, smelting, brass, metal coating, silver refineries, electroplating and several other industrial activities ${ }^{1-2}$. The main symptoms of nickel causes headache, dizziness, nausea and vomiting, chest pain, tightness of the chest, dry cough and shortness of breath, rapid respiration, cyanosis and extreme weakness ${ }^{3}$. Among the methods such as precipitation, oxidation, ultrafiltration, reverse osmosis and elcetrodialysis, ion exchange on natural zeolites seems to be more attractive method. Zeolites have been intensively studied recently because of their applicability in removing trace quantities of heavy metal ions from aqueous solution by utilizing the ion exchange phenomenon ${ }^{4-6}$. 
Zeolites are naturally occurring hydrated alumino silicate minerals. They belong to the class of minerals known as "tectosilicates". The structure of zeolites consists of three dimensional frameworks of $\mathrm{SiO}_{4}$ and $\mathrm{AlO}_{4}$ tetrahedra. The aluminum ion is small enough to occupy the position in the centre of the tetrahedron of four oxygen atom, while the isomorphous replacement of $\mathrm{Si}^{4+}$ by $\mathrm{Al}^{3+}$ produces a negative charge in the lattice ${ }^{7}$. But hitherto only unmodified zeolites have been examined for ion exchange capacity, in which one mole of sodium ion is exchanged for every mole of $\mathrm{Al}^{3+}$ present in the framework of zeolite. There have been reports of modification of zeolite with $\mathrm{H}_{3} \mathrm{PO}_{4}$, for catalytic application. In the present study, ZSM-5 zeolite has been modified for removal of $\mathrm{Ni}^{2+}$ ion from aqueous solution. Each mole of phosphoric acid introduced into the zeolite provides two moles of exchangeable protons, which can be replaced by $\mathrm{Na}^{+}$ions using mild base like $\mathrm{NaHCO}_{3}{ }^{8}$. The results obtained from this study are important for ion exchange and water softening applications.

\section{Experimental}

HZSM-5 zeolite was purchased from Sud-Chemie India Ltd, Mumbai, India. Nickel Sulphate was obtained from Qualigens Fine Chemicals Ltd., Mumbai, India. All other chemicals used were of analytical reagent grade, procured from Rankem Fine Chemicals Ltd, New Delhi, India.

\section{Preparation of modified zeolite}

About $4 \mathrm{~g}$ of HZSM-5 zeolite in $40 \mathrm{~mL}$ of double distilled water was mixed with $0.385 \mathrm{~g}$ of phosphoric acid. The mixture was kept under vigorous stirring at $60{ }^{\circ} \mathrm{C}$ for $3 \mathrm{~h}$ and then evaporated to dryness in an air oven at $120{ }^{\circ} \mathrm{C}$. Phosphoric acid modified zeolite was contacted with $30 \mathrm{~mL}$ of aqueous $\mathrm{NaHCO}_{3}$ solution under vigorous stirring at $60{ }^{\circ} \mathrm{C}$ for $3 \mathrm{~h}$ to obtain the disodium form of an $\mathrm{PNa}_{2}-\mathrm{ZSM}-5$ zeolite. It was then filtered, washed with water and dried in air oven at $120{ }^{\circ} \mathrm{C}$ overnight before use. Figure 1 illustrates the sequence of occurrences in the above treatment. The Na- ZSM-5 zeolite was prepared by adding $\mathrm{NaHCO}_{3}$ solution directly with $\mathrm{H}$ ZSM-5 zeolite.

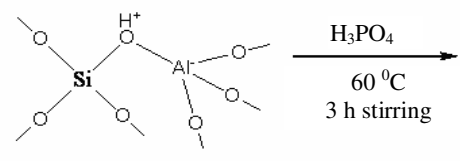

Zeolite-ZSM-5

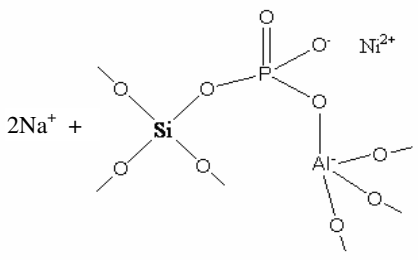

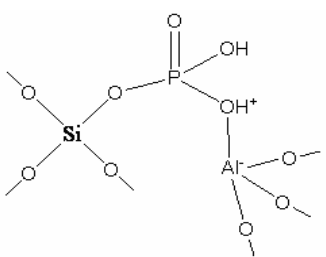

Phosphate modified
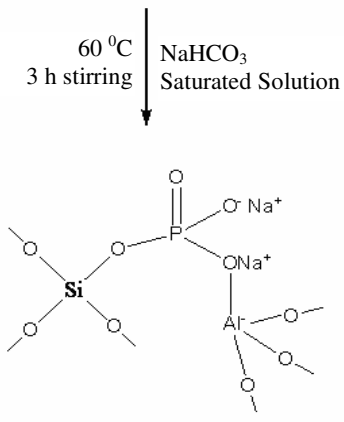

$\mathrm{Na}$ - foam

Figure 1. Reaction schemes illustrating modification of $\mathrm{PNa}_{2-}-\mathrm{ZSM}-5$ zeolites. 


\section{Ion- exchange equilibrium experiments}

The ion exchange capacity of $\mathrm{Ni}^{2+}$ ion with modified Na-ZSM-5 and $\mathrm{PNa}_{2-}-\mathrm{ZSM}-5$ zeolites were studied using a batch method. The batch experiments were carried out with $20 \mathrm{~mL}$ of $50 \mathrm{~m} \mathrm{~mol} \mathrm{Ni}^{2+}$ solution. About $65 \mathrm{mg}$ of the adsorbent was added and the uptake of the zeolite was determined. The $\mathrm{pH}$ of the solution was measured using a $\mathrm{pH}$ meter (Elico Model LI-120, Hyderabad, India). Adjustments of $\mathrm{pH}$ were made with $0.1 \mathrm{M} \mathrm{HCl}$ and $0.1 \mathrm{M} \mathrm{NaOH}$ solutions. The screw cap bottle containing the adsorbate and adsorbent were placed in the thermostatic orbital shaker (Neolab, Mumbai, India) and were shaken at a constant speed of $200 \mathrm{rpm}$. After equilibrium time, the samples were centrifuged and the filtrates were analyzed. The kinetic studies were carried out in magnetic stirrer $50 \mathrm{~m} \mathrm{~mol} \mathrm{Ni}^{2+}$ solutions. About $50 \mathrm{mg}$ of the adsorbent was added. The samples were withdrawn from the stirrer at a regular time intervals and the samples were centrifuged. The absorbance of supernatant solution was measured using Atomic absorption spectrophotometer (SHIMADZU, AA-6300). The uptake and the amount of $\mathrm{Ni}^{2+}$ ion exchanged by the modified zeolites were computed using the following equations.

$$
\begin{gathered}
\text { Re moval efficiency }(\%)=\frac{\left(C_{o}-C_{e}\right)}{C_{o}} \times 100 \\
q_{e}=\frac{\left(C_{o}-C_{e}\right) V}{m}
\end{gathered}
$$

Where, $\mathrm{q}_{\mathrm{e}}$ is the amount of exchanged $\mathrm{Ni}^{2+}$ ions $(\mathrm{m} \mathrm{mol} / \mathrm{g}), \mathrm{C}_{\mathrm{o}}$ and $\mathrm{C}_{\mathrm{e}}$ are the initial and equilibrium concentration of $\mathrm{Ni}^{2+}$ ion in solution $(\mathrm{m} \mathrm{mol} / \mathrm{L})$ respectively $\mathrm{V}$ is the solution volume and $\mathrm{m}$ is mass of the adsorbent $(\mathrm{g})$.

\section{Results and Discussion}

\section{Characterization of modified zeolite}

The BET surface areas of both modified Na-ZSM-5 and PNa $2-\mathrm{ZSM}-5$ zeolites were measured using Smart Sorbs 92 Surface area analyzer where $\mathrm{N}_{2}$ gas was used as adsorbate. The surface areas of modified Na-ZSM-5 and $\mathrm{PNa}_{2}-\mathrm{ZSM}-5$ zeolites were 385 and $422 \mathrm{~m}^{2} / \mathrm{g}$ respectively. The XRD analysis of the modified Na-ZSM-5 and $\mathrm{PNa}_{2}-\mathrm{ZSM}-5$ zeolites was measured using $D$-Max / 111 -VC Model with nickel filtered and $\mathrm{Cu} \mathrm{K \alpha}$ radiation $(\lambda=1.5406 \AA$ ). The X-ray analysis reveals the absences of structural degradation during modification are shown in Figure 2.

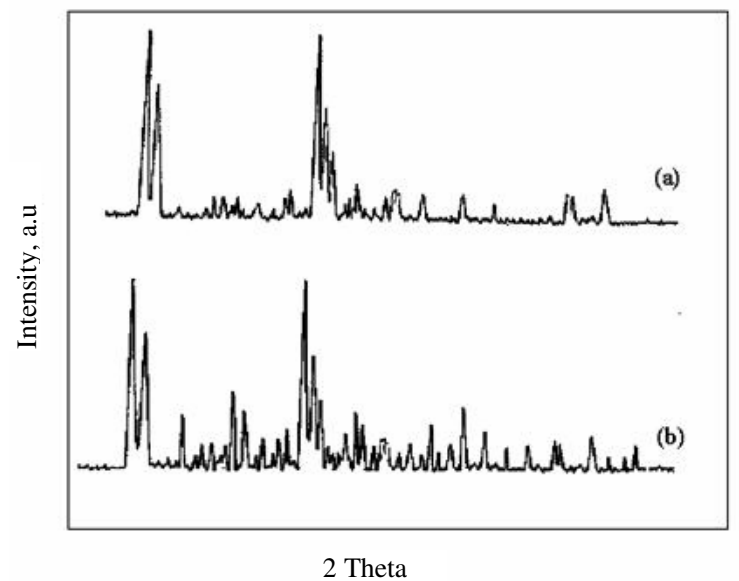

Figure 2. X-ray powder diffraction patterns of (a) Na-ZSM-5 (b) $\mathrm{PNa}_{2}-\mathrm{ZSM}-5$ zeolites. 
Scanning electron microscope (SEM) images were taken to study the surface morphology of zeolite particles using a Joel Jsm-6360 scanning electron microscope. The SEM pictures of the parent H- ZSM-5, Na-ZSM-5 and $\mathrm{PNa}_{2}-\mathrm{ZSM}-5$ zeolites are shown in Figure 3 ( $a, b$ and $c$ ) respectively. The modification of $\mathrm{PNa}_{2}-\mathrm{ZSM}-5$ zeolite might not have resulted any structural degradation of the parent zeolite.
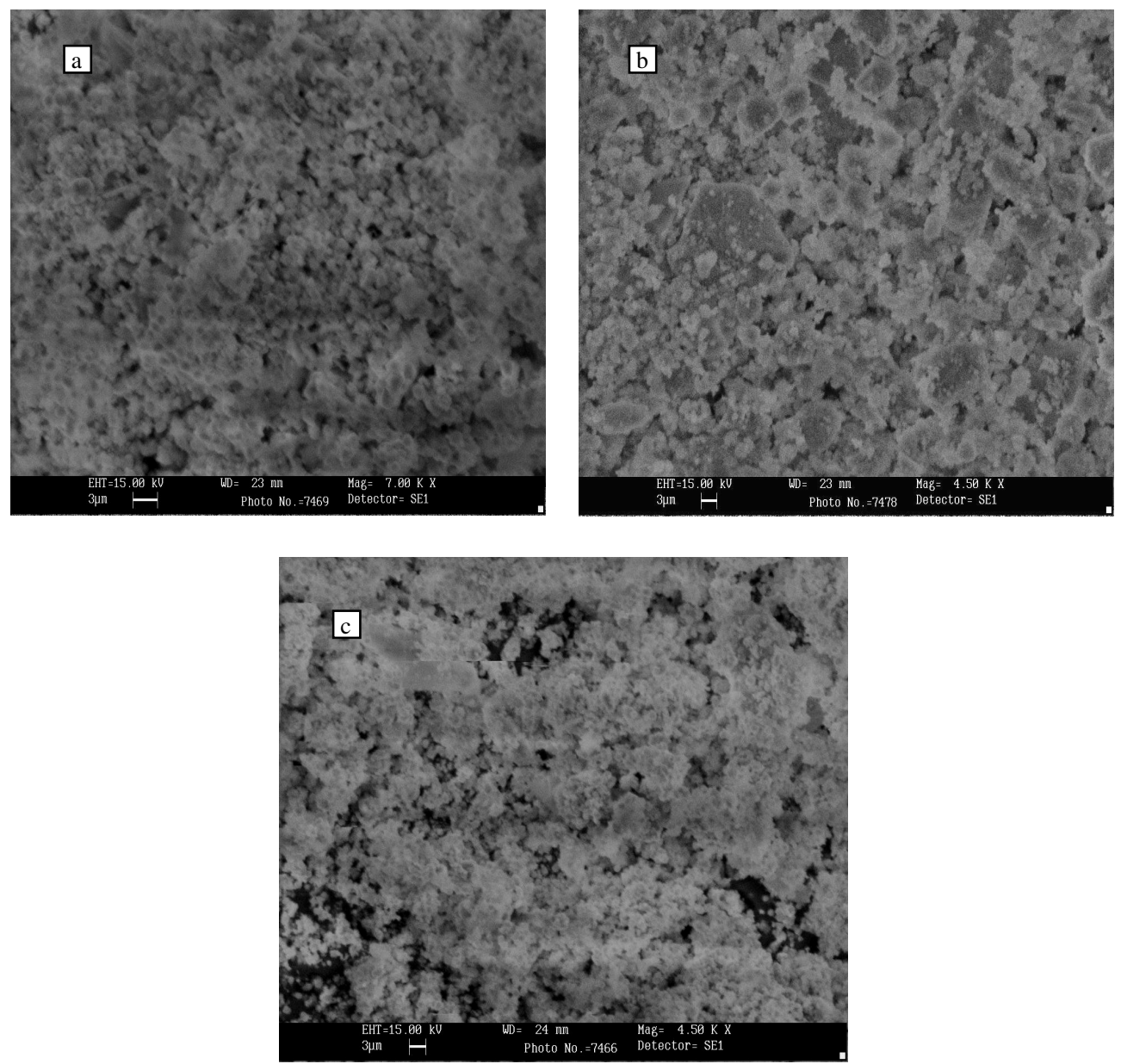

Figure 3. SEM image of (a) H- ZSM-5, (b) Na-ZSM-5 (c) PNa $\mathrm{PN}_{2}$ Z ZSM-5 zeolites.

\section{Effect of $p H$}

The effect of $\mathrm{pH}$ of the suspending medium on nickel removal was studied by performing equilibrium sorption experiments at different $\mathrm{pH}$ values. The results are illustrated in Figure 4. For the $\mathrm{PNa}_{2}-\mathrm{ZSM}-5$ zeolite the uptake efficiency gradually increases as the $\mathrm{pH}$ increases from 3 to 4 in $\mathrm{Ni}^{2+}$. But above $\mathrm{pH} 4 \mathrm{Ni}^{2+}$ uptake was observed which could be attributed to precipitation. The Na-ZSM-5 zeolite also exhibited similar the behavior. Hence optimum $\mathrm{pH}$ range for the removal of $\mathrm{Ni}^{2+}$ was found to be 4 . The $\mathrm{PNa}_{2}-\mathrm{ZSM}-5$ zeolite showed higher uptake than the Na-ZSM-5 zeolites as shown in Figure 4 as it contains more exchangeable $\mathrm{Na}^{+}$ions than latter. 


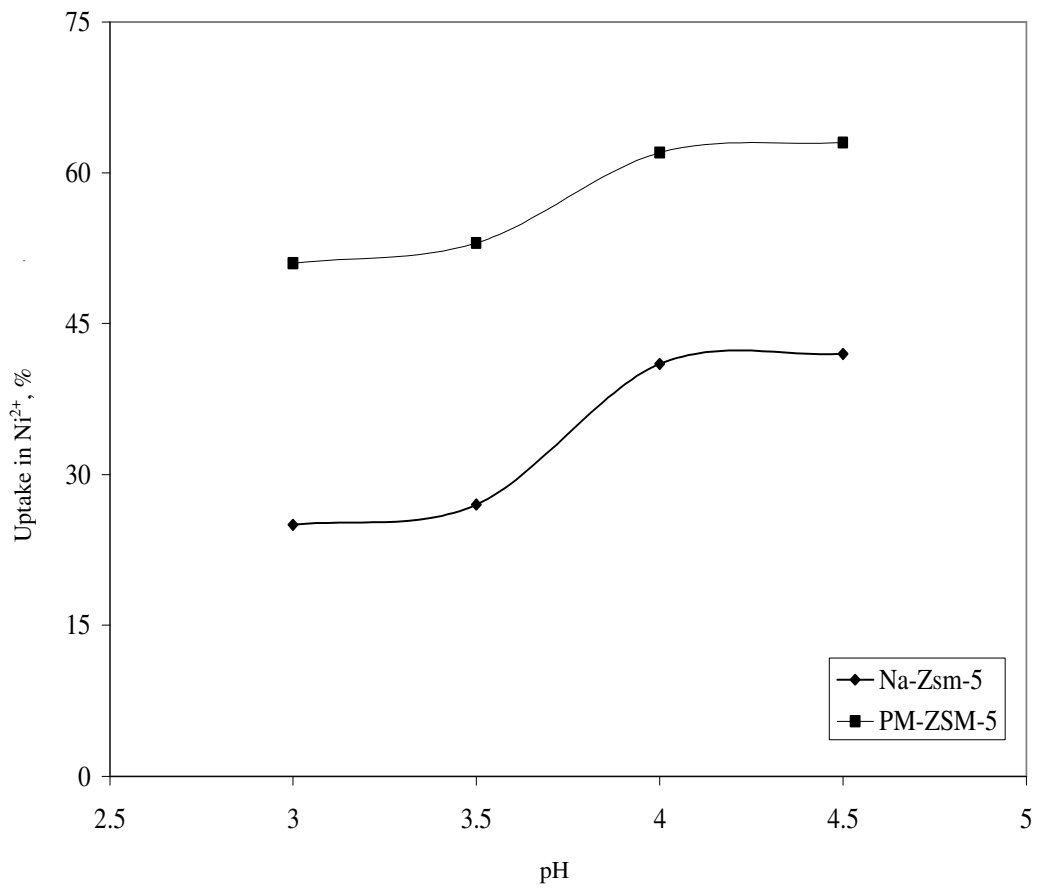

Figure 4. Effect of $\mathrm{pH}$ in $\mathrm{Ni}^{2+}$ ions from aqueous solutions onto ( $) \mathrm{Na}-\mathrm{ZSM}-5$ and ( $(\mathbf{}) \mathrm{PNa}_{2}-$ ZSM-5 zeolites.

\section{Sorption isotherms}

The sorption isotherms for the removal of $\mathrm{Ni}^{2+}$ at different temperatures were studied. It provides information on uptake capabilities and reflects the usual equilibrium process behavior. The Langmuir isotherm could be written ${ }^{9}$ as:

$$
\frac{C_{e}}{q_{e}}=\frac{1}{Q_{o} b}+\frac{C_{e}}{Q_{o}}
$$

where $\mathrm{Q}^{\circ}$ is the monolayer adsorption capacity $(\mathrm{m} \mathrm{mol} / \mathrm{g}$ ) and $\mathrm{b}$ is the constant related to the free energy of adsorption. The logarithmic form of Freundlich equation is given ${ }^{10}$ as:

$$
\log q_{e}=\log K_{f}+\frac{1}{n} \log C_{e}
$$

where $K_{f}$ is the relative adsorption capacity of the adsorbent $(\mathrm{m} \mathrm{mol} / \mathrm{g}$ ) and $1 / \mathrm{n}$ is the constant indicative of the intensity of the adsorption process. The Langmuir isotherm correctly fitted than the Freundlich. The Langmuir as shown in Figure 5. The corresponding Langmuir and Freundlich parameters along with their correlation coefficients are given in Table 1.

The Langmuir constants $\mathrm{Q}^{\circ}$ and $\mathrm{b}$ are increases with increase of temperature showing that the sorption capacity and intensity of the sorption are enhanced at higher temperatures. Hence, the active surface available for sorption has increased with increase of temperature Recently there have been many reports on the sorption of $\mathrm{Ni}^{2+}$ with different adsorbents and the results are presented in Table 2 . 

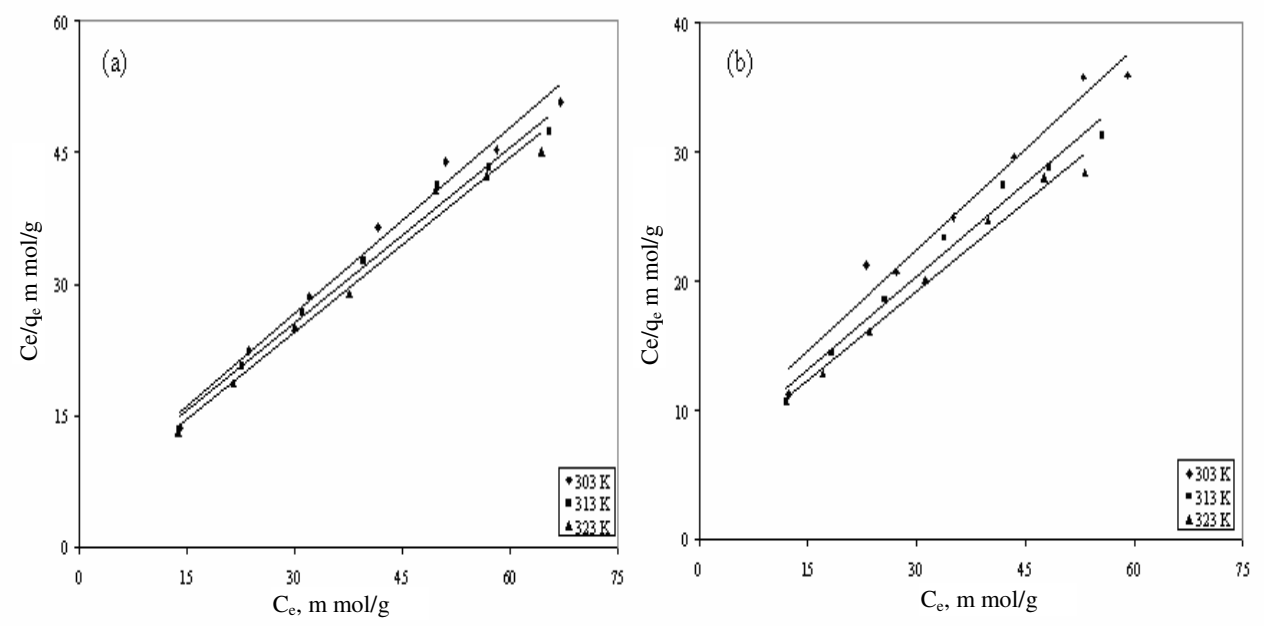

Figure 5. Langmuir isotherm plots for the sorption of $\mathrm{Ni}^{2+}$ ions from aqueous solutions onto (a) Na-ZSM-5 (b) PNa 2 -ZSM-5 zeolites.

Table 1. Langmuir and Freundlich isotherm plots for the sorption of $\mathrm{Ni}^{2+}$ ions from aqueous solutions onto Na-ZSM-5 and PNa 2 -ZSM-5 zeolites.

\begin{tabular}{ccccccc}
\hline \multirow{2}{*}{ Temp $(\mathrm{K})$} & \multicolumn{3}{c}{ Langmuir isotherm } & \multicolumn{3}{c}{ Freundlich isotherm } \\
\cline { 2 - 7 } & $\mathrm{Q}_{\mathrm{o}}, \mathrm{m} \mathrm{mol} / \mathrm{g}$ & $\mathrm{b}, \mathrm{L} / \mathrm{m} \mathrm{mol}$ & $\mathrm{R}_{\mathrm{L}}^{2}$ & $1 / \mathrm{n}$ & $\mathrm{K}_{\mathrm{f}}, \mathrm{m} \mathrm{mol} / \mathrm{g}$ & $\mathrm{R}_{\mathrm{F}}^{2}$ \\
\hline $\mathrm{Na}-\mathrm{Y}$ & & & & & & \\
303 & 0.82 & 0.981 & 0.989 & 0.28 & 0.52 & 0.931 \\
313 & 0.98 & 0.102 & 0.987 & 0.26 & 0.61 & 0.952 \\
323 & 1.04 & 0.115 & 0.992 & 0.24 & 0.72 & 0.962 \\
$\mathrm{PNa}_{2} \mathrm{Y}$ & & & & & & \\
303 & 1.25 & 0.121 & 0.993 & 0.20 & 0.37 & 0.928 \\
313 & 1.32 & 0.135 & 0.996 & 0.18 & 0.40 & 0.975 \\
323 & 1.48 & 0.148 & 0.997 & 0.17 & 0.51 & 0.992 \\
\hline
\end{tabular}

Table 2. Adsorption capacities $\mathrm{Q}^{\mathrm{o}}$ (mg/g) for some zeolite materials

\begin{tabular}{lc}
\hline Adsorbent & $\mathrm{Ni}(\mathrm{II}), \mathrm{mg} / \mathrm{g}$ \\
\hline Kaolinite $^{11}$ & 0.003 \\
Ball Clay $^{11}$ & 0.41 \\
Kaolinite $^{12}$ & 1.70 \\
Na-Montmorillonite $^{13}$ & 3.63 \\
Exfoliated Clay $^{11}$ & 5.91 \\
${\text { Clay treated with } \mathrm{HC}^{14}}_{\text {Natural zeolite }^{12}}$ & 10.9 \\
Clay treated with NaC $^{14}$ & 12.5 \\
Natural zeolite $^{12}$ & 14.5 \\
Modified Na-ZSM-5 zeolite $^{\mathrm{a}}$ & 19.3 \\
$\mathrm{H}_{3} \mathrm{PO}_{4}$ - modified ZSM-5zeolite $^{\mathrm{a}}$ & 28.08 \\
\hline
\end{tabular}

$\left({ }^{a}\right.$ Present study) 


\section{Kinetic studies}

\section{Pseudo-first order kinetic model}

The linear form of Lagergren's first order expression ${ }^{15}$ is written as:

$$
\log \left(q_{e}-q_{t}\right)=\log q_{e}-\frac{k_{1}}{2.303} t
$$

where, $\mathrm{k}_{1}\left(\mathrm{~min}^{-1}\right)$ is the first order adsorption rate constant, $\mathrm{q}_{\mathrm{e}}$ is the amount of metal adsorbed at equilibrium and $\mathrm{q}_{\mathrm{t}}$ is the amount adsorbed at time ' $t$ '. The first order equation of Lagergren does not fit well with the whole range of contact time and is generally applicable over the initial stage of the sorption processes ${ }^{16}$. The first order rate constant is given in Table 3.

\section{Pseudo second order kinetic model}

The linear form of pseudo- second -order rate model and ${ }^{17}$ is expressed as:

$$
\frac{t}{q_{t}}=\frac{1}{k_{2} q_{e}^{2}}+\frac{1}{q_{e}} t
$$

Where, plotting $\mathrm{t} / \mathrm{q}_{\mathrm{t}}$ against " $t$ " for $\mathrm{Ni}^{2+}$ removal at different temperatures is presented in Figure 6. The relationship is linear, and the correlation between the parameter also explains that the process of sorption of each ion follows pseudo second order kinetics. The product $\mathrm{k}_{2} \mathrm{q}_{\mathrm{e}}{ }^{2}$ is the initial sorption rate represented as $\mathrm{h}=\mathrm{k}_{2} \mathrm{q}_{\mathrm{e}}{ }^{2}$ from Table 3. It can be shown that the values of the initial sorption rate ' $h$ ' and the rate constant ' $k_{2}$ ' increase with in increase in temperature.
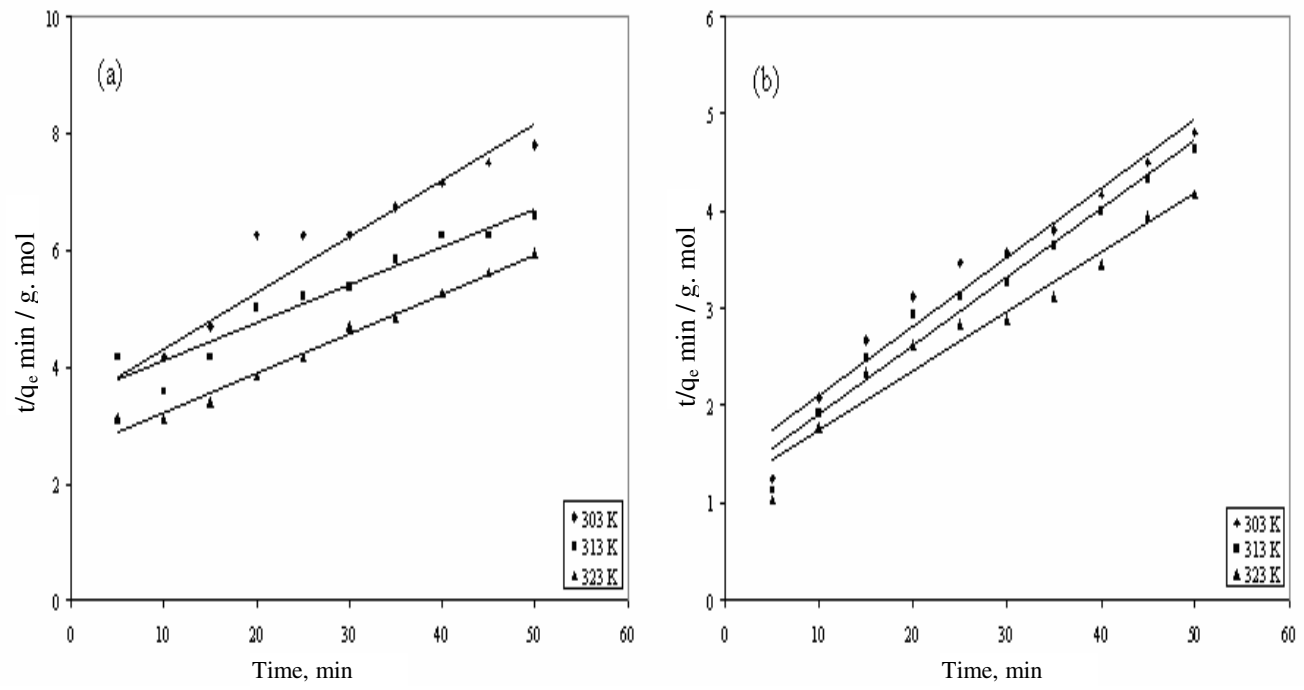

Figure 6. Pseudo-second-order kinetics plots for the sorption of $\mathrm{Ni}^{2+}$ ions from aqueous solutions onto (a) Na-ZSM-5 (b) $\mathrm{PNa}_{2}$ - ZSM-5 zeolites.

The correlation coefficient $\mathrm{R}^{2}$ has an extremely high value, and its calculated equilibrium sorption capacity ' $\mathrm{q}_{\mathrm{e}}$ ' is consistent with the experimental data. The results suggest that the pseudo-second order sorption mechanism is predominant and that the over all rate constant of each ion appears to be controlled by the chemisorption process ${ }^{17}$. 
Table 3. The calculated parameters of the pseudo-first order and pseudo-second order kinetic models of $\mathrm{Ni}^{2+}$ ions from Na-ZSM-5and $\mathrm{PNa}_{2}-\mathrm{ZSM}-5$ zeolites.

\begin{tabular}{cccccccc}
\hline & \multicolumn{3}{c}{ Pseudo-first order } & \multicolumn{3}{c}{ Pseudo-second order } \\
\cline { 2 - 7 } Temp, K & $\begin{array}{c}\mathrm{k}_{1}, \\
\mathrm{~min}^{-1}\end{array}$ & $\begin{array}{c}\mathrm{q}_{\mathrm{e}}, \\
\mathrm{m} \mathrm{mol} / \mathrm{g}\end{array}$ & $\mathrm{R}^{2}{ }_{1}$ & $\begin{array}{c}\mathrm{q}_{\mathrm{e}}, \\
\mathrm{m} \mathrm{mol} / \mathrm{g}\end{array}$ & $\begin{array}{c}\mathrm{h}, \\
\mathrm{m} \mathrm{mol} / \mathrm{g}\end{array}$ & $\begin{array}{c}\mathrm{k}_{2}, \\
\mathrm{~g} / \mathrm{m} \text { mol min }\end{array}$ & $\mathrm{R}_{2}{ }^{2}$ \\
\hline $\mathrm{Na}-\mathrm{Y}$ & & & & & & & \\
303 & 0.029 & 0.610 & 0.981 & 0.72 & 0.521 & 0.517 & 0.993 \\
313 & 0.035 & 0.728 & 0.952 & 0.85 & 0.752 & 0.682 & 0.989 \\
323 & 0.041 & 0.819 & 0.983 & 0.91 & 0.851 & 0.714 & 0.995 \\
$\mathrm{PNa}_{2}-\mathrm{Y}$ & & & & & & & \\
303 & 0.032 & 0.852 & 0.937 & 0.98 & 0.901 & 0.782 & 0.991 \\
313 & 0.047 & 0.938 & 0.975 & 1.02 & 1.237 & 0.915 & 0.993 \\
323 & 0.061 & 1.351 & 0.981 & 1.15 & 1.582 & 1.210 & 0.998 \\
\hline
\end{tabular}

\section{Conclusions}

From this study it is concluded that phosphoric acid modified ZSM-5 zeolite can be a better adsorbent than the parent zeolite. The modification can also be extended to other zeolites for enhanced sorption properties. The removal efficiency increases with the increase in temperature and hence sorption process is endothermic in nature. The adsorption isotherm data fit well with Langmuir isotherm while the kinetic data were represented by pseudosecond order kinetic model. This study forecasts that treatment of wastewater, particularly heavy metal ion removal and softening of hardwater, could be better carried out with the modified zeolite. The results of this study cleary envisage that such modified zeolites can very well be recommended for wastewater treatment and control of environmental pollution.

\section{References}

1. Howari F M, Abu-Rukah Y and Gooddell P C, Int J Environ Pollut., 2004, 22, 5-14.

2. Kadirvelu K, Thamariselvi K and Namasivayam C, Sep Purif Technol., 2001, 24, 497- 505.

3. Parker P, Encyclopedia of Environmental Sciences, $2^{\text {nd }}$ Ed., McGraw Hill, New York, 1980.

4. Shanableh A and Kharabsheh A, J Hazard Mater., 1996, 45, 207-217.

5. Misaelides P, Godelitsas A, Charistos V, Ioannou D and Charistos D, J Radioanal Nucl Chem., 1994, 183(1), 159-166.

6. Stylianou M A, Inglezakis V J, Moustakas K G, Desalination, 2007, 215, 33-142.

7. Dyer A, Introduction to Zeolite Molecular sieves, John Wiley \& Sons, Chichester, 1988.

8. Zhuang J, Ma D and Yang G, J Catalysis, 2004, 228, 234-242.

9. Langmuir I, J Am Chem Soc., 1918, 40, 1361-1403.

10 Freundlich H M F, Zeitschrift fur physcikalische Chemie (Leipzig), 1906, 57A, 385-470.

11. Chantawong V, Harvey N W and Bashkin V N, Water Air Soil Pollut., 2003, 148, 111-120.

12. Kurniawan T A and Chan Y S, Sci Total Environ., 2006, 366, 409-426.

13. Abollino O, Aceto M and Maiandrino M. Water Res., 2003, 37, 1619 -1624.

14. Hawash S, Farash J Y and El-Geundi M S, Adv Sci Technol., 1994, 9, 244-248.

15. McKay G and Ho Y S, Water Res., 1999, 33, 585-587.

16. McKay G and Ho Y S, Process Biochem., 1999, 34, 451-460.

17. Ho Y S, J Colloid Interface Sci., 2003, 262, 307-308. 


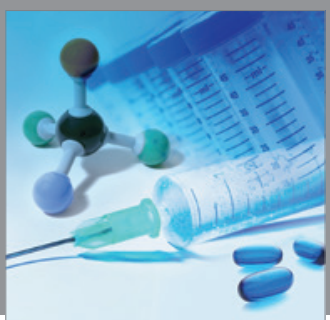

International Journal of

Medicinal Chemistry

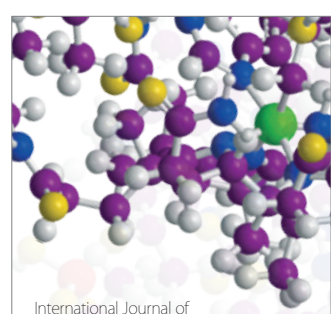

Carbohydrate Chemistry

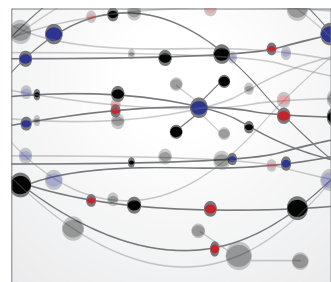

The Scientific World Journal
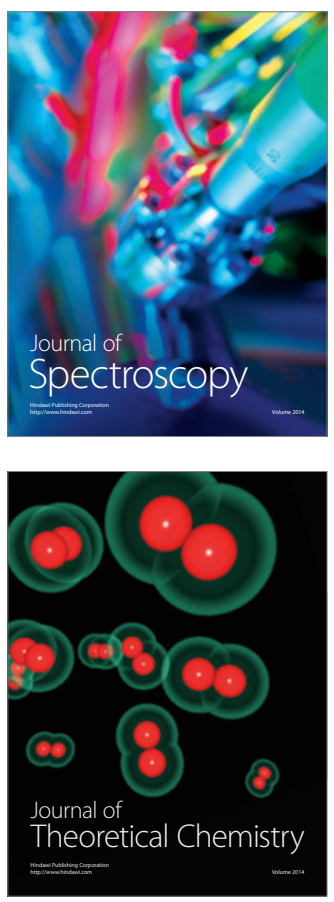
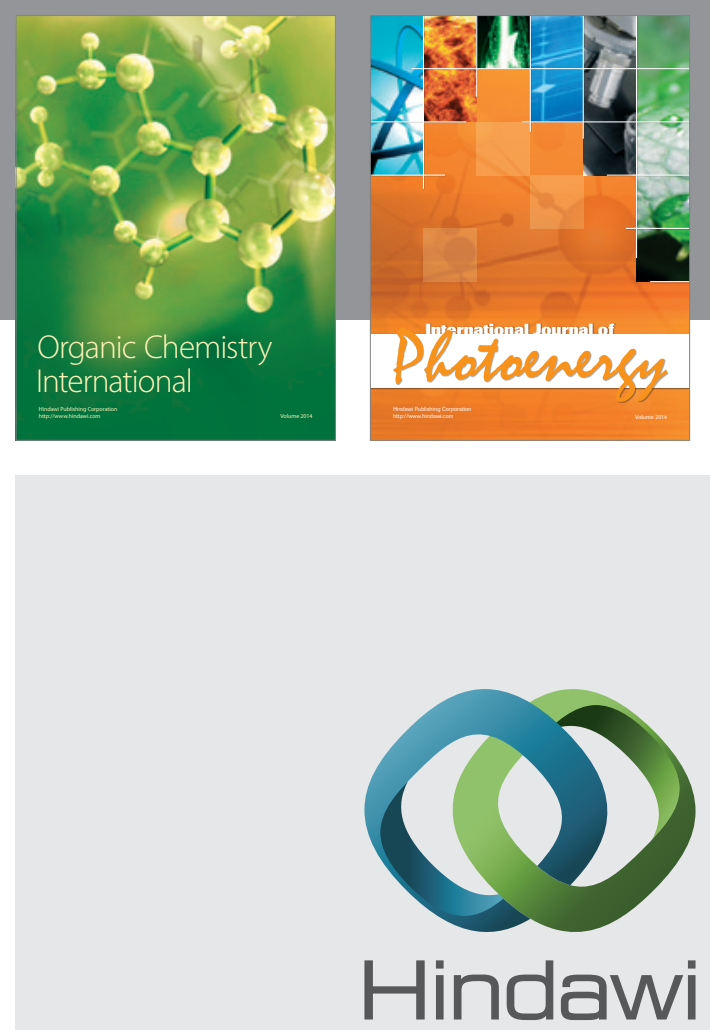

Submit your manuscripts at

http://www.hindawi.com
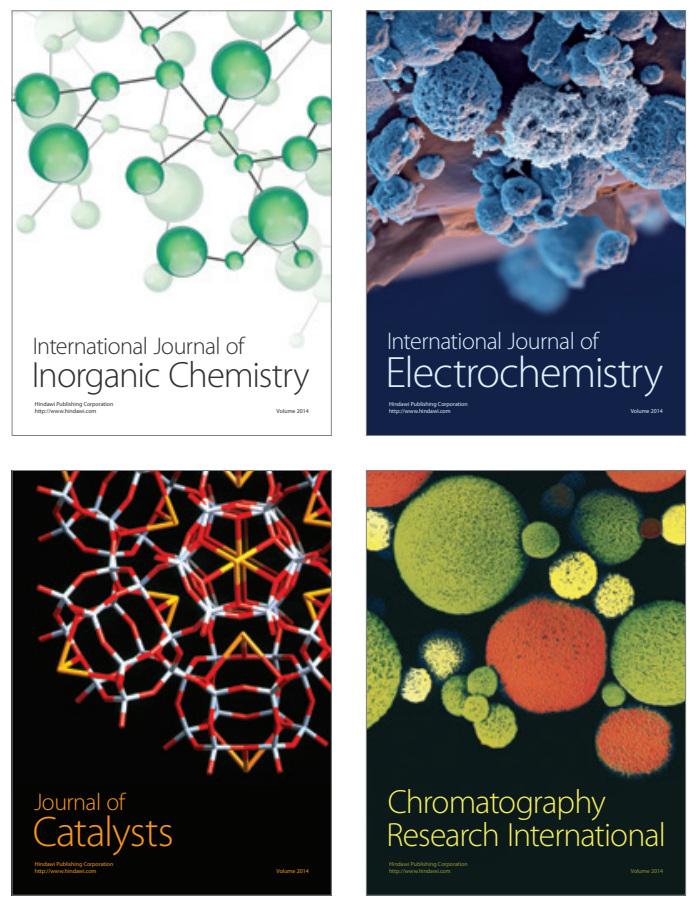
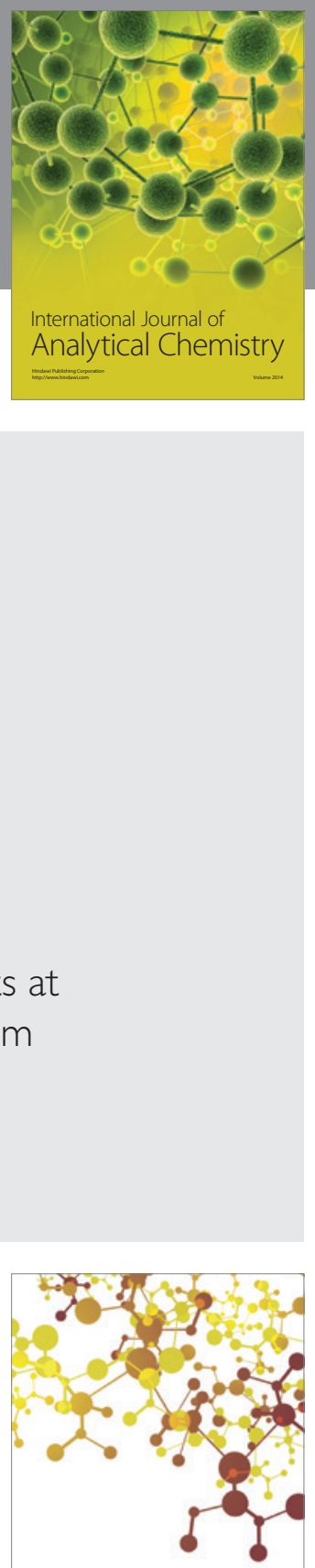

Journal of

Applied Chemistry
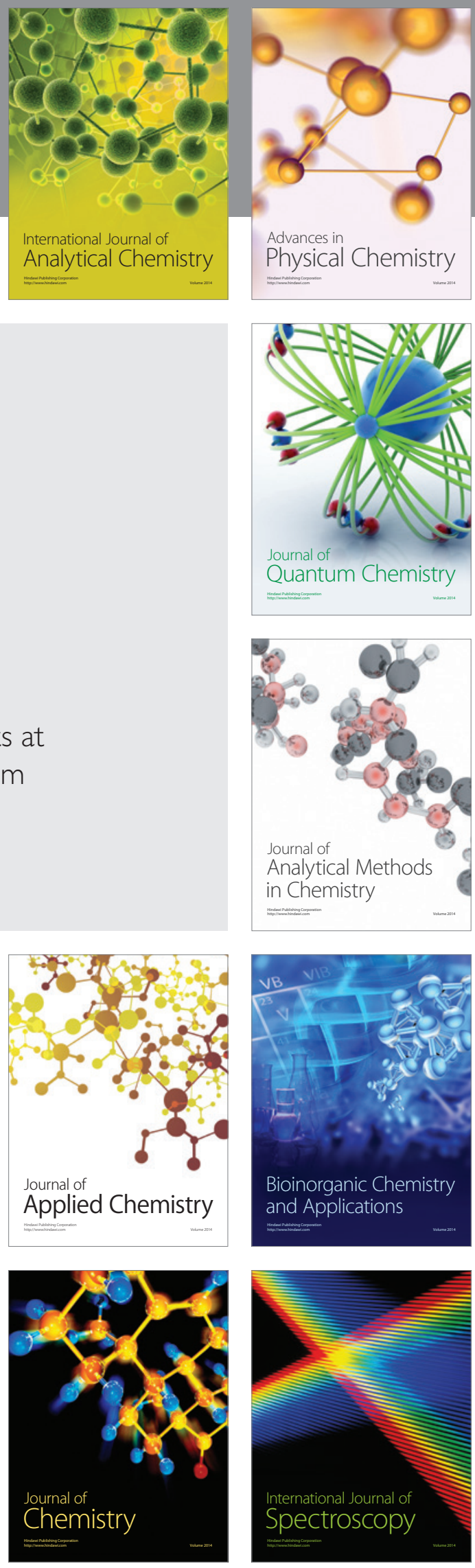